\title{
Screening for diabetic microalbuminuria in routine clinical care: which method?
}

\author{
J P H Shield, L P Hunt, J D Baum, C A Pennock
}

\begin{abstract}
The measurement of albumin/creatinine ratios and simple albumin concentrations in early morning urine specimens were evaluated to establish which was the best screening test for those likely to have microalbuminuria by the reference standard analysis of timed overnight urine specimens. The measurement of an albumin/creatinine ratio with a cut off of $\geqslant 2.0 \mathrm{mg} / \mathrm{mmol}$ was found to be suitable with a specificity of $93 \%$ and sensitivity of $97 \%$. (Arch Dis Child 1995; 72: 524-525)
\end{abstract}

Keywords: microalbuminuria, screening.

Microalbuminuria is currently the best predictor we have for later onset overt nephropathy in insulin dependent diabetes mellitus (IDDM) ${ }^{1}$ Both the Diabetes Control and Complications Trial and angiotensin converting enzyme inhibitor intervention studies show that the progression of microalbuminuria can be modified in children and young adults. It seems appropriate therefore, for steps to be taken nationally to identify those diabetic children with abnormal urinary albumin excretion. ${ }^{23}$

Microalbuminuria is defined by general consensus to be an albumin excretion rate on a timed urine specimen of $20-200 \mu \mathrm{g} / \mathrm{min} .^{4}$ However, in routine practice the collection and measurement of timed urine collections is inconvenient for both patients, clinicians, and laboratories. There is a need for a screening methodology with a high specificity and sensitivity for identifying those patients most likely to have true microalbuminuria (as measured on timed specimens). This study was designed to identify the method of analysis and cut off point of most benefit in a clinical setting to define those needing further evaluation of albumin excretion.

Sensitivity, specificity, positive and negative predictive value for microalbuminuria (in a timed specimen 20-200 $\mu \mathrm{g} / \mathrm{min}$ ) for the two methods of analysis and various cut off points from an aliquot of an early morning specimen

\begin{tabular}{|c|c|c|c|c|}
\hline $\begin{array}{l}\text { Method of } \\
\text { analysis and } \\
\text { cut off points }\end{array}$ & $\begin{array}{l}\text { Sensitivity } \\
(\%)\end{array}$ & $\begin{array}{l}\text { Specificity } \\
(\%)\end{array}$ & $\begin{array}{l}\text { Positive } \\
\text { predictive } \\
\text { value (\%) }\end{array}$ & $\begin{array}{l}\text { Negative } \\
\text { predictive } \\
\text { value (\%) }\end{array}$ \\
\hline \multicolumn{5}{|c|}{ Concentration of albumin ( $\mathrm{mg} / \mathrm{l})$} \\
\hline$\geqslant 20$ & 90 & 91 & 54 & 99 \\
\hline$\geqslant 17$ & 90 & 86 & 44 & 99 \\
\hline \multicolumn{5}{|c|}{ Albumin/creatinine ratio $(\mathrm{mg} / \mathrm{mmol})$} \\
\hline$\geqslant 1.5$ & 100 & 85 & 47 & 100 \\
\hline$\geqslant 2 \cdot 0$ & 97 & 93 & 63 & 100 \\
\hline$\geqslant 2.5$ & 94 & 94 & 66 & 99 \\
\hline$\geqslant 3 \cdot 0$ & 90 & 96 & 74 & 99 \\
\hline$\geqslant 3.5$ & 77 & 97 & 75 & 97 \\
\hline$\geqslant 4 \cdot 0$ & 71 & 97 & 73 & 94 \\
\hline$\geqslant 5 \cdot 0$ & 61 & 99 & 86 & 95 \\
\hline
\end{tabular}

\section{Subjects and methods}

One hundred and four children and young adults (median age 19.0 years; range $10 \cdot 6-23 \cdot 5$ years) with IDDM were asked to collect three overnight, timed urine specimens supported by suitable written and verbal (if necessary) instructions given to each individual or parents. On the three days before visiting the clinic, the patients were told to empty their bladder before retiring to bed recording the time, and to collect all the urine passed, again recording the time, on waking.

The volume and timing of each collection was recorded before analysis. A $2 \mathrm{ml}$ aliquot of urine was taken from each specimen and analysed for albumin concentration allowing estimation of an albumin excretion rate with the timing and volume data already recorded. In addition, this aliquot was used to evaluate the albumin/creatine ratio as an early morning specimen. The albumin concentration was measured by immunoturbidimetry and the creatinine by a modified Jaffé method.

The sensitivity, specificity, and predictive values for the various methods and cut off points were estimated as described by Altman and Bland. 56

\section{Results}

There were 247 timed urine collections suitable for analysis. The prevalence of positive tests for microalbuminuria was $12 \cdot 5 \%$. The sensitivity, specificity, positive and negative predictive values for the methods and individual cut off points are given in the table.

\section{Discussion}

The prevalence of microalbuminuria in a diabetes clinic of children and adolescents under 19 years of age is estimated at between $5 \%$ and $15 \% .^{1}$ Although the significance of microalbuminuria for predicting progression to overt nephropathy and eventual renal failure is still uncertain there is currently a need to evaluate its prevalence and progression in childhood. Moreover, the targeting of those thought to be at greatest risk of microvascular disease is warranted as possible therapeutic options become available. Studies in adults have suggested that an early morning albumin/creatinine ratio has the greatest sensitivity for defining microalbuminuria with a cut off level of $3.5 \mathrm{mg} / \mathrm{mmol}^{4}$ This study, on a younger population, also shows that the albumin/creatinine ratio offers better sensitivity and specificity than albumin concentrations alone, but that the cut off level (where
Correspondence to: Dr Shield.

Accepted 16 March 1995 
the total proportion of misclassifications of both groups is kept to a minimum) should be set lower at $2 \mathrm{mg} / \mathrm{mmol}$ with a sensitivity of $97 \%$ (95\% confidence interval (CI) 83 to $100 \%)$ and specificity of $93 \%$ (95\% CI 89 to $96 \%$ ). In order to pick up every case of microalbuminuria the level would have to be reduced to $1.5 \mathrm{mg} / \mathrm{mmol}$ but this would lead to a large number of false positive cases being recruited into the demanding discipline of timed urine collections.

If we are to tackle the prevention of long term microvascular and macrovascular complications of diabetes we must first have effective methods of screening which are convenient for the patient, suitably specific and sensitive. We suggest that measuring the early morning albumin/creatinine ratio meets these criteria.

This study was financially supported by the friends of David Ashmead.

1 Shield JPH. Microalbuminuria and nephropathy in childhood diabetes. Practical Diabetes 1994; 11: 146-9.

2 The Diabetes Control and Complications Trial Research Group. The effect of intensive treatment of diabetes on the development and progression of long-term complications in insulin-dependent diabetes mellitus. N Engl f Med 1993;

3 Cook J, Daneman D, Spino M, Sochett E, Perlman K, Bafle JW. Angiotensin converting enzyme inhibition therapy to decrease microalbuminuria in normotensive children with insulin-dependent diabetes mellitus. F Pediatr 1990; 117: 39-44.

4 Marshall SM. Screening for microalbuminuria: which measurement? Diabet Med 1991; 8: 706-11.

5 Altman DG, Bland JM. Diagnostic tests 1 : sensitivity and specificity. BMF 1994; 308: 1552.

6 Altman DG, Bland JM. Diagnostic tests 2: predictive values. $B M \mathcal{A}$ 1994; 309: 102 . 